CRÍTICA, Revista Hispanoamericana de Filosofía

Vol. XXVII, No. 79 (abril 1995): 47-53

\title{
UNA PROPUESTA DE THOMAS SIMPSON SOBRE CONTEXTOS OBLICUOS
}

\author{
RaÚl Orayen
}

Instituto de Investigaciones Filosóficas

UNAM

1. Unas palabras sobre Formas lógicas, realidad y significado

Cuando se publicó Formas lógicas, realidad y significado por primera vez (1964), yo recién comenzaba mis estudios de filosofía y era muy poco lo que sabía de ella. Me había interesado ya por la lógica - en gran medida gracias a un estupendo curso de Gregorio Klimovsky - y había apreciado sobremanera la precisión y claridad, rasgos característicos de esta disciplina. Pero también me interesaba la especulación filosófica acerca de cuestiones metafísicas y epistemológicas. El libro de Simpson me abrió un panorama que me resultó apasionante. En el texto se trataban muchos problemas ontológicos y epistémicos que surgen al analizar determinadas teorías lógicas, o problemas de esa naturaleza que pueden aclararse con la aplicación de ideas y métodos lógicos. En Formas lógicas... confluían así distintas problemáticas e ideas que me habían llamado la atención. La lectura del libro comenzó a orientarme hacia áreas que después ocuparían gran parte de mi vida intelectual, particularmente la filosofía del lenguaje y de la lógica.

El texto de Thomas contenía muchas sorpresas para mí. Hasta ese momento yo asociaba los libros sobre temas es- 
trictamente filosóficos con la solemnidad y el lenguaje algo oscuro. Formas lógicas... era claro, irreverente y divertido. Pude ver entonces que la profundidad conceptual y el rigor del pensamiento no estaban reñidos con la gracia y la fluidez. Me hice entonces "simpsonadicto" y seguí leyendo ávidamente los textos de Thomas, a veces no publicados. Mi vocación hacia ciertos temas y cierta manera de tratarlos se fue reforzando con rapidez. Mirando hacia atrás, me sorprende hasta qué punto influyeron los escritos de Thomas en la dirección de mis propias investigaciones. Mi reciente libro Lógica, significado y ontología muestra desde el título sus afinidades con el de Thomas. Hasta sus silencios tuvieron efectos sobre mis trabajos. Hacia el final de las "Palabras preliminares" de su libro, Thomas dice que posterga para alguna obra posterior, dedicada al concepto de inferencia formal, el análisis de la noción de forma lógica. Thomas no escribió esa obra. Pero me motivó tanto que uno de los temas centrales de mi libro Lógica, significado... es precisamente la noción de forma lógica. De mis artículos publicados, son varios los que abordan temas y problemas que conocí por primera vez leyendo la obra de Simpson que estoy recordando. Como estoy reconociendo la influencia que tuvo la obra de Thomas sobre mi propio trabajo, convendría insertar en este punto la pudorosa aclaración usual de que Simpson no es responsable de los errores que yo haya podido cometer, etc. Pero no veo por qué lo voy a eximir totalmente de estas responsabilidades. ¿Y si los problemas que tomé de él no fueran importantes, después de todo? En ese caso, yo habría cometido un error existencial espantoso al dedicarles tanto esfuerzo. Y Thomas tendría gran parte de la culpa, por haber escrito un libro increíblemente atractivo sobre los temas en cuestión, libro capaz de alterar vocaciones e influir sobre existencias ajenas. 
He notado a veces que soy más hábil formulando un argumento lógico que refiriendo una deuda personal. Espero, sin embargo, que estas líneas apresuradas dejen entrever al lector la importancia que tuvo para mi vida intelectual el encuentro con Formas lógicas, realidad y significado.

2. Una propuesta de Simpson sobre la eliminación de contextos oblicuos

Es conocido el hecho de que hay contextos en los cuales la aplicación de la regla de sustitutividad de idénticos puede llevar de la verdad a la falsedad. Un ejemplo clásico es

(1) Jorge IV quiso saber si Scott era el autor de Waverley.

(2) Scott $=$ el autor de Waverley.

Por lo tanto,

(3) Jorge IV quiso saber si Scott era Scott.

Es obvio que con el uso ordinario de las expresiones que aparecen en (1), (2) y (3), las dos primeras oraciones pueden resultar verdaderas y la tercera falsa. En el Apéndice II de la segunda edición de Formas lógicas... ("Sobre la eliminación de los contextos oblicuos"), Simpson señala que la solución Frege-Church de esta paradoja tiene dos componentes: la parte del diagnóstico y la parte del remedio (véase especialmente p. 223). El diagnóstico postula que el argumento anterior (y otros similares) es un caso de falacia de equívoco. En las premisas (1) y (2), 'Scott' se usa con sentidos diferentes; otro tanto ocurre con 'el autor de Waverley'. En (2) 'Scott' se usa con su sentido habitual (directo, en la terminología de Frege) y denota una persona. En (1), en cambio, por efecto del contexto especial en que figura allí, tiene sentido oblicuo y denotación oblicua. La denotación oblicua coincide con el sentido directo: 'Scott' denota en (1) el sentido que tiene en (2) (y 
un sentido no es una persona). Una situación exactamente paralela se cumple en el caso de 'el autor de Waverley'. Una ambigüedad sistemática del lenguaje ordinario (debido a la cual los nombres aparecen con un sentido y denotado "directos" en los contextos normales y con sentidos y denotados distintos, "oblicuos" en algunos contextos epistémicos, modales, etc.) provoca paradojas como la que hemos visto, que son, según este enfoque, falacias de equívoco de un tipo especial. ${ }^{1}$

¿Cómo remediar estos problemas? El diagnóstico sugiere que debería perfeccionarse el lenguaje ordinario para evitar la ambigüedad sistemática antes mencionada. Cuando los nombres tienen sus sentidos y denotados directos (los más habituales) podemos usarlos tal como se lo hace en el lenguaje ordinario. Habida cuenta de que en algunos contextos (como la premisa (1) de nuestro ejemplo), los nombres denotan algo que no es su denotado habitual sino su sentido habitual, podríamos introducir alguna notación especial para hacer referencia a ese sentido. Esto es lo que propone Simpson en el apéndice mencionado. Una vez que se haya suprimido la oblicuidad (porque los nombres ya no tendrían denotado oblicuo en algunos contextos: en tales contextos, se usaría una notación especial para hacer referencia al sentido que quiere mencionarse), piensa Simpson que "tendría validez irrestricta el principio de inferencia conocido como ley de Leibniz [lo que llamé antes regla de sustitutividad de idénticos]" y se cumpliría entonces que "Si dos nombres denotan el mismo individuo, son inter-

1 Una explicación total de la paradoja debe incluir la consideración de que 'Scott' y 'el autor de Waverley' no son sinónimos. Si lo fueran, sus sentidos directos coincidirían y las dos expresiones denotarían lo mismo en (1) (porque allí denotan sus sentidos directos), por lo cual el reemplazo de una expresión por otra en (1) sería permisible y no conduciría a falsedades. Simpson hace notar que los sentidos directos de ambas expresiones difieren (en su observación (i) de p. 223). 
cambiables en todos los contextos salva veritate" (p. 223). Sin embargo, la manera en que Simpson elimina los contextos oblicuos no da lugar a una validez irrestricta del principio de inferencia antes mencionado, lo cual mostraré a continuación.

Simpson construye una manera de eliminar la oblicuidad en ciertos contextos. Se ocupa de contextos oblicuos gobernados por verbos de actitudes proposicionales y operadores modales, con la restricción adicional de que en tales contextos no deben aparecer "variables ligadas por cuantificadores externos" (p. 226). Además “toda oración cuya oblicuidad deseemos suprimir debe ser interpretable como una combinación de nombres" (p. 227). Prescindiendo de detalles, ${ }^{2}$ lo que hace Simpson es lo siguiente: dada una oración que constituye un contexto oblicuo de la clase estudiada, cada uno de los nombres que aparece en ella con denotación oblicua es reemplazado por el mismo nombre rodeado por corchetes; se introduce la convención de que una expresión compuesta por corchetes que rodean un nombre denota el sentido directo del nombre en cuestión. ${ }^{3}$ La oblicuidad desaparece: ya no ocurre —al menos en las oraciones construidas a partir de oraciones del tipo bajo análisis - que un nombre pueda tener un denotado habitual en los contextos más usuales y otro -su sentido directo- en contextos especiales; cuando se quiera denotar ese sentido se usará la notación con corchetes introducida

2 Entre ellos el hecho de que quizás hay una jerarquía infinita de denotados oblicuos de un nombre dado. Sólo me ocupo de la solución de Simpson de los casos de oblicuidad de la categoría más baja. Su solución es más general y la observación crítica que haré a la misma es generalizable también. El lector deberá buscar también en el texto de Simpson la explicación de por qué una sucesión de nombres de sentidos puede denotar una proposición, y el papel de los paréntesis para demarcar la proposición en cuestión.

3 Un uso adecuado de subíndices permite proporcionar denotaciones oblicuas de niveles más altos. 
especialmente. Pero Simpson no ha advertido un detalle: en la notación con corchetes siguen apareciendo (dentro de los corchetes) los nombres que antes aparecían en los contextos oblicuos eliminados. Si después de eliminada la oblicuidad se pudiera aplicar irrestrictamente el principio de Leibniz -como cree Simpson-, se podrían reemplazar esos nombres que aparecen dentro de los corchetes de acuerdo con el principio citado. Sin embargo, cuando se procede así reaparecen paradojas similares a las originales. Consideremos la inferencia siguiente:

(1') Jorge IV quiere saber si es verdadera ([Scott] [=] [el autor de Waverley])

(2) Scott $=$ el autor de Waverley

Por lo tanto,

(3') Jorge IV quiere saber si es verdadera ([Scott] [=] [Scott $])$.

Naturalmente, entendiendo las premisas y la conclusión de acuerdo con las convenciones introducidas por Simpson, pueden ser verdaderas las dos primeras oraciones y falsa la última. Jorge IV puede querer aclarar una duda respecto de la proposición mencionada en ( $l^{\prime}$ ) y no tener dudas respecto de la que se menciona en (3'). De modo que la eliminación de contextos oblicuos diseñada por Simpson no permite la aplicación irrestricta del principio de Leibniz.

Un defensor del texto de Simpson puede aducir valientemente que en ( ${ }^{\prime}$ ') y (3') no aparecen 'Scott' y 'el autor de Waverley'. Aun usando una noción técnica de aparecer en una oración, tal defensa es difícilmente razonable. Pero la dificultad señalada es bastante superficial y se la puede evitar modificando ligeramente la propuesta de Simpson. Se trata simplemente de construir una notación para denotar el sentido de un nombre en que el nombre aparezca deformado de acuerdo con un método que permita saber cuál es 
el nombre al que quiere aludirse pero sin que el nombre aparezca en el texto. Por ejemplo, podemos convenir en que para denotar el sentido de un nombre se usará la expresión formada por un par de corchetes rodeando el nombre en cuestión, pero con un asterisco intercalado entre su primera y segunda letra. El sentido de 'Scott' será denotado entonces por '[S*cott]'. Conseguimos así una notación para sentidos de nombres que nos permite individualizar cuál es el nombre cuyo sentido nos interesa pero sin permitir que haya una aparición del nombre en un contexto en que su reemplazo por otro de la misma denotación directa puede dar lugar a paradojas. ${ }^{4}$

La simplicidad de la solución que he dado a la dificultad señalada muestra la escasa importancia teórica de la misma. Un lector podría sospechar que hay tesis de Simpson expuestas en el apéndice citado que esconden problemas más profundos. Sin embargo, debiera hacerse notar que Simpson dedica el apéndice a analizar problemas internos de un enfoque semántico determinado (la teoría Frege-Church), sin suscribir todas las tesis del enfoque en cuestión. Dada la brevedad del texto que he analizado, es notable la cantidad de aspectos de la teoría Frege-Church que reciben clarificación en estas páginas. Tal clarificación es oportuna: como el enfoque de Frege acerca de las actitudes proposicionales es en la actualidad un punto de referencia en los trabajos sobre el tema, es muy útil tener en claro algunos rasgos complejos de la teoría fregeana que Thomas explica en detalle con su conocida habilidad expositiva.

Recibido: 19 de enero de 1995

4 La solución debe complicarse un poco teniendo en cuenta que pueden aparecer nombres que contengan otros nombres, como 'la capital de Francia', pero no entraré en detalles tediosos. 